\title{
Causes of Air Pollution in Bangladesh's Capital City and Its Impacts on Public Health
}

\author{
Kudrat-E-Khuda (Babu) $\dagger$
}

Department of Law, Daffodil International University, Dhaka, Bangladesh

†Corresponding author: Kudrat-E-Khuda (Babu); kekbabu@gmail.com

Nat. Env. \& Poll. Tech. Website: www.neptjournal.com

Received: $14-04-2020$

Revised: 03-05-2020

Accepted: 25-06-2020

Key Words:

Air pollution

Dhaka city

Air quality

Human health

\begin{abstract}
Air is one of the precious natural resources which is essential for living beings. Pollution in the urban areas like Cairo, Delhi, Mexico and Dhaka far surpasses the acceptable limits set by the World Health Organization (WHO). Urban air pollution in the South Asian region is approximated to cause more than 300,000 deaths and billions of cases of respiratory disease per year. In Bangladesh, about 200,000 people die each year due to air pollution as the WHO estimates in 2018. The air in Dhaka city, the capital of Bangladesh, has worsened to a level that the city has been identified as one of the most polluted cities in the world. Taking the problem with utmost importance into consideration as it is related to public health, air pollution is being treated as one of the priority issues. The level of pollution in the roadside environment is deeply connected with the density of motor vehicles plying on the roads. This situation is expected to worsen further in the upcoming days due to the increasing number of motor vehicles resulted from rapid economic growth and industrialization. This paper aims to provide the present status of air pollution in Dhaka city and some specific recommendations for making the city a better living place by reducing its air pollution.
\end{abstract}

\section{INTRODUCTION}

Man is responsible, in many ways, for the present status of the environmental disasters that are on the rise all over the world. It is a common scenario and true feature that air pollution is one of the most concerning and alarming issues in the present world among the variety of manmade disasters. Generally, air pollution can be described as a condition of the atmosphere where different elements are present at concentrations that are higher than the normal ambient concentrations producing an effect measurable on humans, animals, vegetation or materials (Alam 1999). Here the term 'substances' refers to any chemical compound or elements which are natural or manmade and may be airborne. Theses chemical compounds or elements are nothing but exist as solid particles, liquid drops or gases. There are many substances in the atmosphere which may be harmful or benevolent. However, the term 'measurable effect' logically does not focus on those substances which cause unwanted effects. It is of no doubt that air is becoming more worsened day by day, and both human activities and natural phenomena are responsible for it. In Bangladesh, vehicular and industrial emissions are the two great sources of air contamination (EEA 2016). Particularly, the cities are subject to much air pollution as they have more vehicles plying on the road and industries than the rural areas. In the current years, air pollution has been given the best priority among environmental issues not only in Asian countries but also in the other countries of the world. In many parts of the world, exposure to air pollution, at present, has become the prime threat to human health. In particular, in cities, the urban population has been victimized of respiratory and other airborne diseases due to the emission issues that have increased the death rate significantly (WHO 2018). Dhaka is the capital of Bangladesh and also the centre point of most of the commercial activity, and is facing this problem acutely. Being centre of the country, it has a vast number of industries in and around the city, i.e. ready-made garment (RMG) manufacturing industries, different types of mills, industries, factories along with chemicals industries, brickfields and so on (Mahmud 2011). Moreover, the city has too much population causing it polluted which is a matter of great concern. In contrast, other cities of Bangladesh like Rajshahi, Khulna, Bogura and Chattagram have much lesser health-related problems caused by air pollution. The increasing numbers of motor vehicles, industrial development on a random basis and continuous housing have made ambient atmospheric conditions deteriorated. The result of this study will assist decision-maker in formulating national policies to combat air pollution.

\section{MATERIALS AND METHODS}

All the relevant data and information were collected and used from primary and secondary sources of air pollution. 
The information from different books, journals, booklets, proceedings, newsletters, souvenirs, and consultancy report that are available in the libraries of Daffodil International University, Bangladesh was compiled for the study. Maximum necessary support was taken from internet searching. The study presents a synopsis of several monitoring and surveys conducted by the author on ambient concentrations of lead, black smoke, nitrogen oxides, $(\mathrm{NOx})$, Ozone $\left(\mathrm{O}_{3}\right)$ particular matters, carbon monoxide $(\mathrm{CO})$ and sulphur dioxide $\left(\mathrm{SO}_{2}\right)$. The selected data (collected from the selected stations between 2018 and 2019) reveal that the ambient air of the capital city of Bangladesh (Dhaka) is polluted more than 55 per cent of the year. The Air Quality Index observed in different locations of the Dhaka city shows that the roadside environment of $70 \%$ areas is severely polluted while that of $30 \%$ is heavily polluted as per the WHO's standards. The level of pollution in the roadside environment is deeply connected with the density of different types of motor vehicles moving on the roads regularly. This situation is expected to worsen further in the upcoming days due to the increasing number of motor vehicles resulted from rapid economic growth and industrialization. The present study provides some considerable recommendations to reduce air pollution in Dhaka, the capital city of Bangladesh.

\section{RESULTS AND DISCUSSION}

Air pollution in Dhaka city: The industrial and vehicular emissions are the two main great sources of air pollution in Dhaka city. The industrial emission sources like thousands of ready-made garment factories (RMG), chemical industries, brick kilns, pharmaceutical industries, etc. produce not only an enormous amount of smokes but also dust, different types of gases, fumes, etc. which are mainly responsible for air pollution. Moreover, the tanneries at Hazaribag in Dhaka city emit ammonia $\left(\mathrm{NH}_{3}\right)$, chlorine $(\mathrm{Cl})$, hydrogen sulphide $\left(\mathrm{H}_{2} \mathrm{~S}\right)$ and some other chemicals which are the highly poisonous and the cause of public health complaints. The number of vehicles is also increasing day by day in the capital city of Bangladesh as the population is increasing and the unabated urbanization is going on, all this lead to a rise in air pollution (Begum et al. 2011). The baby-taxies, tempos, mini-trucks, motorcycles and other vehicles with two-stroke engines are the prime source of air pollution in Dhaka city, which are recently observed by the scientific research conducted by the specialists of the Department of Environment (DoE), Bangladesh along with other relevant organizations in Bangladesh. Currently, more than 500000 motor vehicles including about 65,000 baby-taxies are plying in Dhaka city alone (Franchini 2019). In addition, a high number of trucks and mini-buses, which are overloaded, poorly maintained and very old are also plying on the streets emitting gases and smoke. Indeed, more than $80 \%$ of vehicles playing on the streets of Dhaka city daily are defective and these types of vehicles emit black smoke far beyond the limits. Vehicles using petrol and diesel emit black smoke which contains unburned fine carbon particles. In particular, the quality standards of air vary from one place to another place due to its geographical location. Areas with more industrial and commercial institutions are highly contaminated than the residential areas. The areas Mohammadpur, Farmgate, Manik Mia Avenue, Tejgaon, Mohakhali, Gabtoli, Mirpur, Bonosree, etc. are the worst affected areas in Dhaka city. Generally, 400 micrograms/cubic meter is the allowable limit for the concentration of suspended particulars in air. But the concentration of suspended particulars goes up to 3,000 micrograms/cubic meter (at the Farmgate area of the Dhaka city) as per the study conducted in 2019. This study found that the presence of SO in the air at the Farmgate area of Dhaka city is more than three times than the usual permissible limit. The presence of 100 micrograms SO in the air is the maximum permissible limit for per cubic meter. However, the presence of 385 microgram sulphur-dioxide was found in the air of Farmagte area. Correspondingly, in the Tejgaon Industrial area, the similar picture of the air pollution was also found where the maximum concentration of suspended particles was 1,849 micrograms/cubic meter (in January of 2018) though the permissible limit is 500 micrograms/cubic meter. Generally, the months from December to March are considered as the dry months in Bangladesh and during this period the capital city Dhaka has the highest concentration of air pollution.

Air pollutants level in 2018 in Dhaka city: In March 2018, the average emission of air pollutants at Bangladesh Agricultural Research Council, Farmgate, Sangsad Bhaban and Darussalam Road, Mirpur in association with Standard Air Quality in Bangladesh are presented in Fig. 1.

Traffic volume in Dhaka city: Currently, Dhaka city is the most polluted city in the world as per the report released by Switzerland-based IQ Air and the seventh most populated city in the world (Fig. 3). More than 20 million people live here and the population is increasing randomly as people are coming here from different parts of Bangladesh for jobs and work. This overpopulated city has been declared as the most polluted urban city worldwide, and its traffic volume is the largest relative to other cities of Bangladesh. Fig. 2 and Fig. 4 show how the number of vehicles is increasing in Dhaka each year. The non-motorized vehicles in particular in road intersections, are significantly responsible for the severe congestion and thus enhance emission problems. Of total trips, the contribution of non-motorized transport 


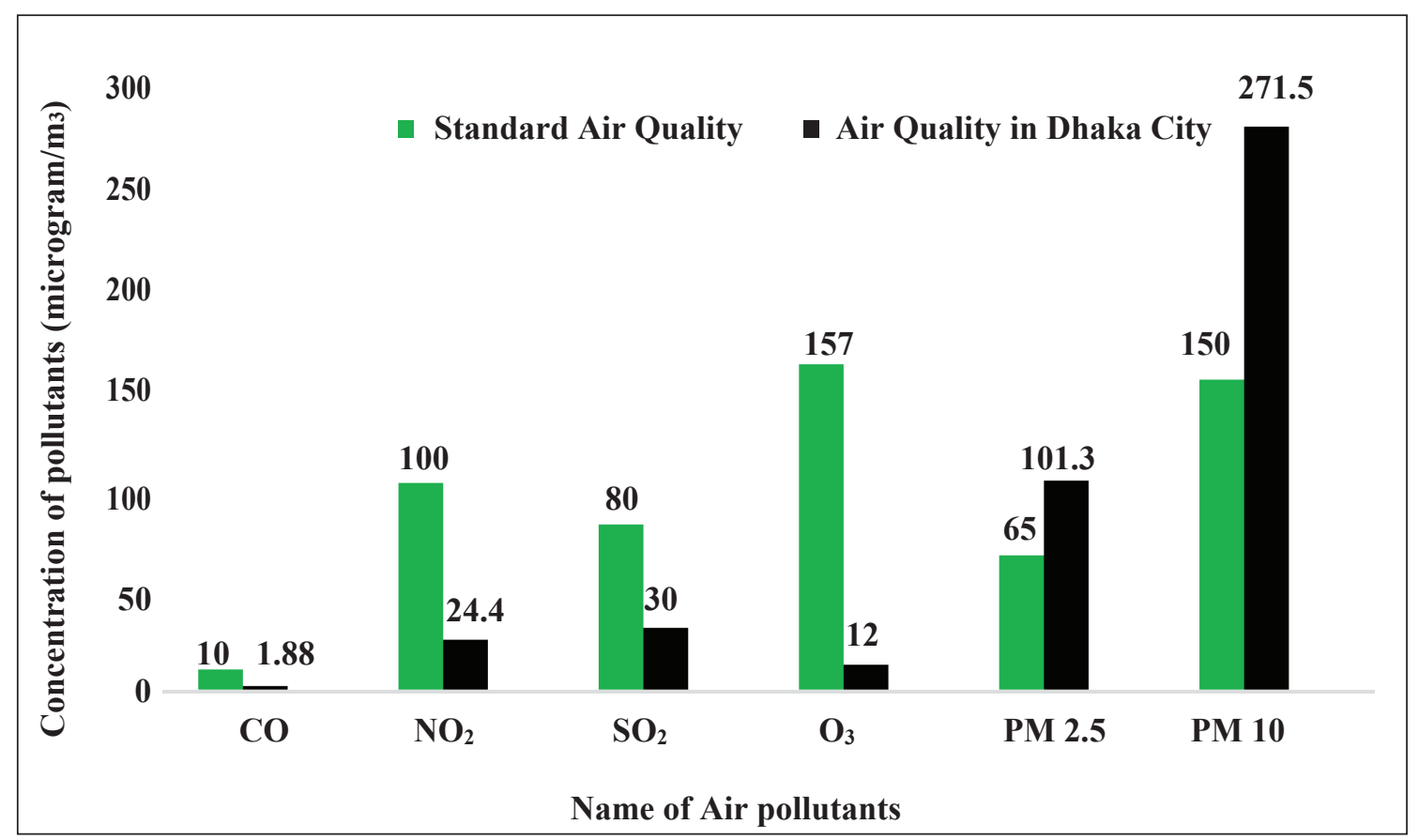

(Source: Department of Environment, Bangladesh)

Fig.1: Average ambient of air pollutants in Dhaka City.

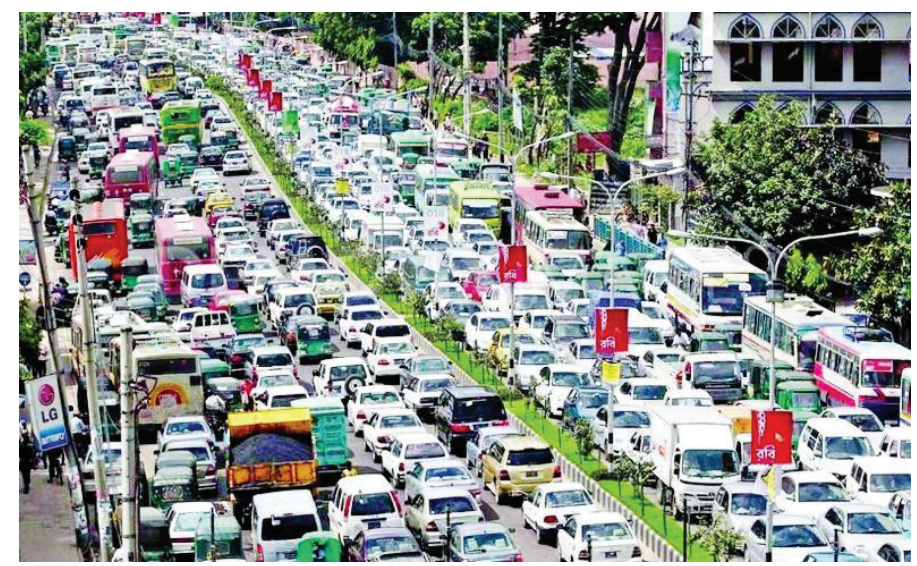

Fig. 2: Traffic jam in Dhaka city.

(NMT) is $80 \%$ while that of motorized transport (MT) is only $5.9 \%$.

Air particulate matter and gaseous pollutants: The continuous air quality monitoring station was first set-up in 2018 by the Department of Environment at the premises of the Parliament Building, the most important public institution in the country which is located in the centre of the city, in an attempt to monitor air quality and control air pollution in
Dhaka city. It was observed that concentration of pollutants in the air was high during October to April and the PM was mostly constituted of $\mathrm{PM}_{10}$ and $\mathrm{PM}_{2.5}$.

Over the period from November 2019 to January 2020, the author found the presence of the $\mathrm{Pb}$ in the air of Dhaka city at $14.6 \mu \mathrm{g} / \mathrm{m}^{3}$, though the maximum allowable limit for $\mathrm{Pb}$ in air, as per the WHO guideline (1 year average), is $0.51 \mu \mathrm{g} / \mathrm{m}^{3}$. 


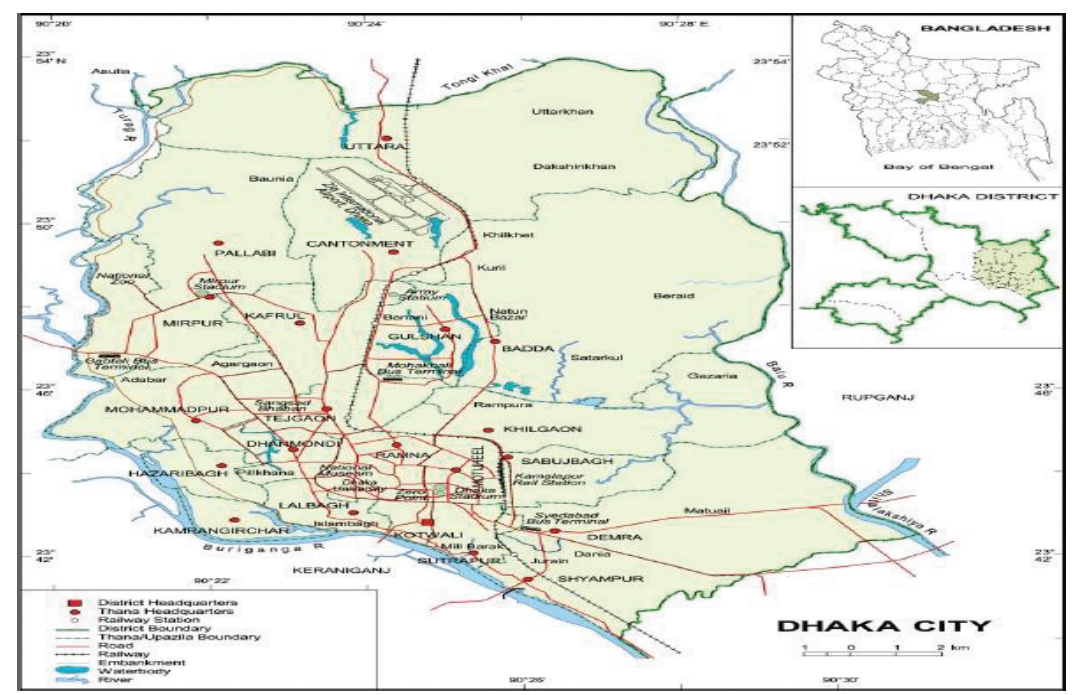

Fig. 3: Map of the Dhaka City (The area of Dhaka is $1,353 \mathrm{~km}^{2}$, of which Dhaka City Corporation occupies $276 \mathrm{~km}^{2}$. The city is situated between $23^{\circ} 42^{\prime}$ and $23^{\circ} 54^{\prime}$ north latitude and $90^{\circ} 20^{\prime}$ and $90^{\circ} 28^{\prime}$ east longitude).

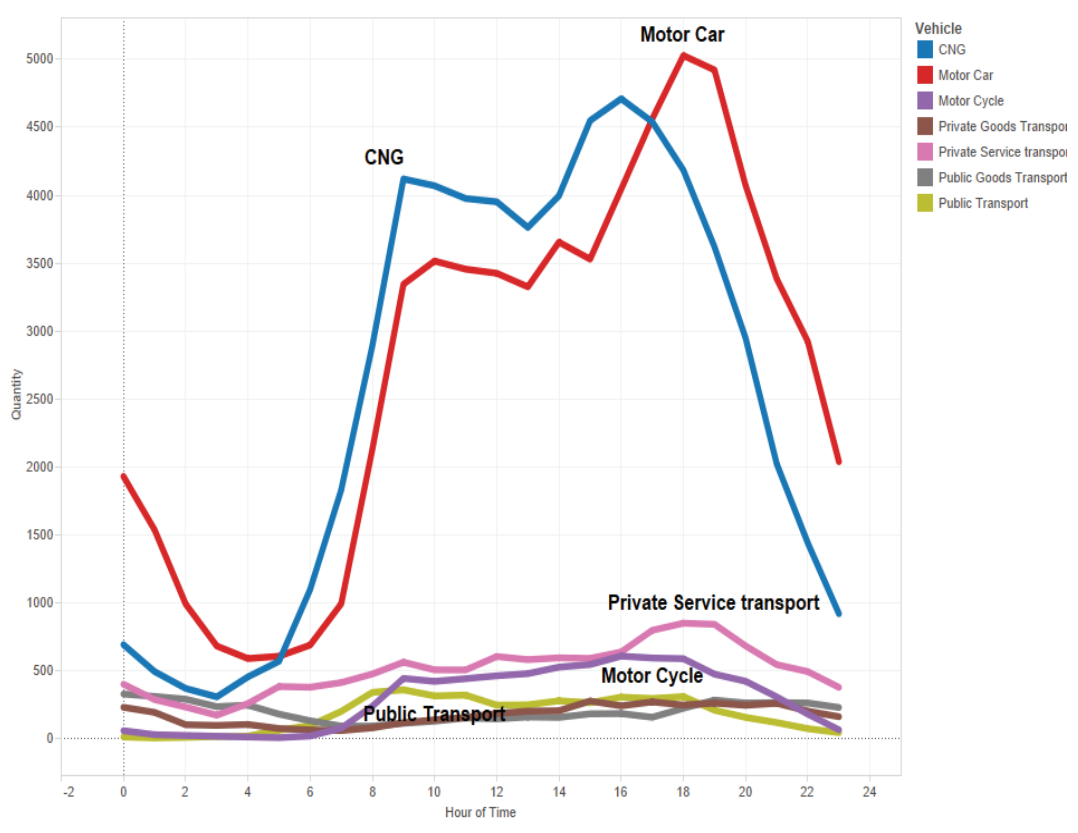

Fig. 4: Number of vehicles is increasing in Dhaka each year.

Dhaka city air quality index: According to an article published in the Dhaka Tribune on January 30, 2020, air is graded as "hazardous" in nature. The article states that the Dhaka city has earned the top position among the cities with worst air in the Air Quality Index. United News of Bangladesh in another report terms the city to be 'dangerous' with an AQI score of 408. Around 301 and 500, an AQI level includes emergency health alarms and is much more likely to affect the community as a whole.

To make the public anticipation about the air pollution problems clear, some calculations have been carried out as per the collected data as well as the projected air quality standards, to provide some AQI numbers. On the basis of Air Quality Rating, the index is measured for every single pollutant. For a number of pollutants, AQI is obtained from the geometric mean of the Air Quality Ratings. The findings 
are abridged in Table 1. It has been found in the observation that the roadside environment of $70 \%$ areas, if we take the WHO's standards into consideration, is severely contaminated while that of $30 \%$ is heavily contaminated. Even, if we take the standards set by the Government of Bangladesh into consideration, severe contamination is found in all areas. As per the guidelines of WHO, Mohakhali, Jatrabari and Panthopath are the most polluted areas where the AQI is above 200. The AQI is above 100 even at roads besides residential areas like Dhanmondi and Jigatola.

Suspended particulate matters (SPM) in Dhaka city air: With the increasing industrialization, urbanization and infrastructure construction, the air is becoming more polluted day by day. In dry season, air pollution reaches its peak. The vehicular emissions, the industrial emissions and the waste burning are highly responsible for air pollution. Particulate matters $\mathrm{PM}_{10}$ refer to those substances which are of $10 \mu \mathrm{m}$ in size and these are considered as the rigorous health exposures (Flossmann et al. 2018). Brick kilns, cement, steel and ceramic factories are the sources from where $\mathrm{PM}_{10}$ is emitted. Per year, among the sources, a cement factory emits most contributing 130 tones $\mathrm{PM}_{10}$ while a brick kiln adds 83 tons. Along with this, a steel re-rolling mill and a ceramic factory also contribute 17 tons and 20 tons of $\mathrm{PM}_{10}$ every year. As per the report of the State of Global Air 2019, approximately $72 \%$ of domestic households use solid fuels that also leads to air pollution. A survey was carried out at several places including those of busy roads of Dhaka city where the department took 8 hours measurements. The survey shows SMP concentrations of $660-2450 \mu \mathrm{g} / \mathrm{m}^{3}$ at the area of Farmgate of Dhaka city though the minimum SMP concentrations, as fixed for the Standard for Commercial Area, is $400 \mu \mathrm{g} / \mathrm{m}^{3}$. During the dry season (from December to March), the SMP trends are highly elevated because of increment in dust and the open burning.

\section{THE VARIOUS AIR POLLUTANTS AND THEIR EFFECTS ON HUMAN HEALTH}

Air is one of the natural resources that are essential for animals and human beings. It is impossible to survive for human beings without air. So, the pollution of air can interfere with human health, and it is only in recent times that mankind has realized to what extent this interference is sustainable (Chafe et al. 2014). Mr. Md Shahab Uddin, the Environment, Forests and Climate Change Minister of Bangladesh said on 25 November 2019 to the journalists that Dhaka city has the most polluted air in the world because

Table 1: Air quality levels in the roads of Dhaka City.

\begin{tabular}{|lllll|}
\hline Standard & $\begin{array}{l}\text { Category of Air } \\
\text { Quality }\end{array}$ & $\begin{array}{l}\text { Range of the Estimated } \\
\text { Value of AQI }\end{array}$ & $\begin{array}{l}\text { Average AQI for } \\
\text { the Category }\end{array}$ & $\begin{array}{l}\text { Number of Locations } \\
\text { in Category }\end{array}$ \\
\hline AQI Calculated on the basis of Bangladesh Standard & Severely Polluted & $209-454$ & 318 & $49(100 \%)$ \\
Calculated AQI on the basis of WHO Standard & Severely Polluted & $131-215$ & 167 & $34(70 \%)$ \\
& Heavily Polluted & $102-124$ & -114 & $14(30 \%)$ \\
\hline
\end{tabular}

Source: Biswas (2020).

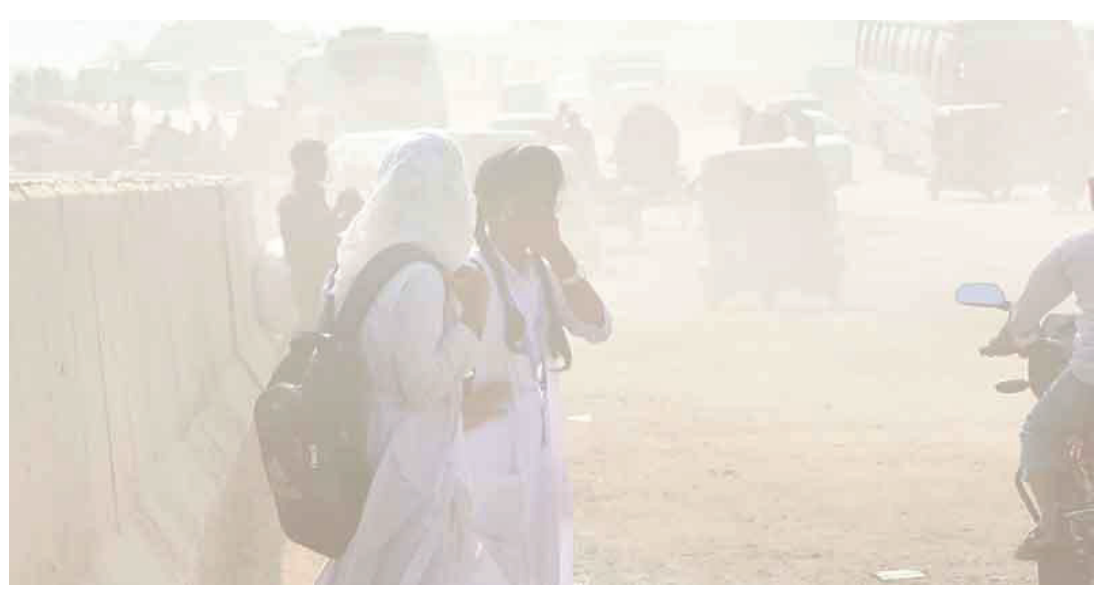

Fig. 5: The common scenario of air pollution in Dhaka city. 
the level of air pollution has been increasing here day by day (The Independent, 27 November 2019). Taking the problem with utmost importance into consideration as it is related to public health, air pollution is being treated as one of the priority issues. Contamination in the urban areas like the New Delhi of India, Linfen of China, Faisalabad of Pakistan and Dhaka far surpasses the acceptable limits set by the WHO. An epidemiological study shows that air pollution is liable for the tens of thousands of extra deaths as well as the billions of dollars of loss of productivity each year in the developing countries like Bangladesh (Faiz et al. 1996). As per the recent estimates of the World Bank, more than 450000 people die and billions of cases of respiratory diseases occur in the South Asian region along with Dhaka due to the urban air pollution where the children and old men are the most vulnerable to the air pollution. In 2018, WHO estimated that about 200000 people died in Bangladesh each year due to the polluted air. Moreover, indoor and outdoor air pollution killed more than one lac people in 2017 in South Asia, as per the study report conducted by the US-based Institute for Health and Evaluation as well as the Health Effects Institute. As per a medical report, in Bangladesh perspective, four of the top 10 death-causing diseases are directly related to air pollution, i.e. stroke (5\%); lung cancers $(13 \%)$; chronic obstructive pulmonary disease $(7 \%)$; chemic heart disease $(6 \%)$, and the lower respiratory tract infections (7\%). Besides, the effects of different types of air pollutants on human health are as below.

i. Carbon dioxide: $\mathrm{CO}_{2}$ plays an important role in the planetary temperature structure as it is the major absorber of infrared radiation.

ii. Carbon monoxide: The high concentration of $\mathrm{CO}$ in blood makes it difficult for our heart to pump blood through the blood vessel that takes blood away from the heart to all parts of our body.

iii. Hydrocarbons: HCs cause convulsion of the central nervous system and may also form $\mathrm{O}_{3}$ (ozone) with the oxides of nitrogen.

iv. Lead: $\mathrm{Pb}$ is liable for the kidney and irreversible brain damage. $\mathrm{Pb}$ is more dangerous for young children.

v. Sulphur dioxide: Sulphur dioxide is a colourless gas having a sharp odour. It irritates the eyes (Gonzalez et al. 2013). It also affects the functions of the lungs along with the respiratory system ( $\mathrm{Li}$ et al. 2015). Moreover, it also causes cough, aggravation of asthma and mucus secretion (Padula et al. 2013).

vi. Ozone: The excess $\mathrm{O}_{3}$ in the air affects human health in different ways. It is responsible for asthma, premature birth and the lung malfunctioning (Zaidi et al. 2011, Yamamoto et al. 2014). Ozone also affects cardiac development (Kannan et al. 2007). It is increasing the hospital admissions for asthma in children, especially in the South Asian countries along with Bangladesh (Lin et al. 2017).

vii. Oxides of nitrogen: NOx affect directly and indirectly human health and cause eye irritation, headache and breathing problems, and chronically reduce the function of our lungs and corrode teeth (Nishimura et al. 2013). Besides, NOx can affect human beings indirectly by damaging the ecosystems as they rely on the land and in water harming the plants and animals (Mc et al. 2007). An estimated 70,000 deaths occur from exposure to $\mathrm{NO}_{2}$ whereas in Bangladesh it is estimated that 3000 premature deaths occur each year from exposure to PM and NOx (Faruque 2017). As per the study conducted in Hong Kong, $10 \mu \mathrm{g} / \mathrm{m}^{3}$ increase in NOx corresponded to an adjusted OR of 1.25 (95\% CI 1.16 to 1.36) for diagnosed asthma in 6 to 13 years old babies (Liu et al.2014).

\section{STEPS TO REDUCE AIR POLLUTION IN DHAKA CITY}

Among the 17 Sustainable Developments Goals (SDGs), there are two specific goals related to the air and environment and these two SDGs are SDG 3 and SDG 11 that must be addressed if we want to materialize the importance of the air control management because a clear reference has been made in the duo goals about the air pollution. This issue not only mentioned the duo goals but it has multiple drivers and related sustainability impacts linking around 14 out of United Nations 17 SDGs. These goals, related objectives and indicators are linked with multiple drivers, while the best outcome to ensure the clean air can be achieved via the integrated approach of air quality management. Otherwise, the dream behind the SDGs will remain quite meaningless and unfulfilled. The Bangladesh government along with the Dhaka City Corporations can consider the following recommendations to reduce the air pollution in Dhaka city.

- The air of Dhaka city usually becomes severely polluted in December-March. Therefore, air pollution varies from one season to another season. So, the air control strategy needs to be unique and it will not be like the other overall management policies of the government.

- For the developing strategy for air quality control, the priority pollutants need to be determined soon. Determining pollutants and health hazards resulting from poor air quality of a particular area or location can help form a solution to that area or location.

- Along with other pollutants in the air, the increasing level of dust pollutants is gradually becoming a serious health threat to the residents of Dhaka city which is of 
great concern nowadays. For that reason, a cost-effective control system should be set-up immediately that includes assimilating control measures in light of reducing the sources of dust and waste points. To meet the SDG objectives and indicators, other dominant source points like construction sites, brickfields, the total transportation system of Dhaka city, etc. should be taken into consideration.

- To reduce air pollution, the citizens of Dhaka city can play an important role individually or unitedly. People can play a vital role to reduce air pollution by driving less and driving wisely; using fuel-efficient vehicles, public transport, walking, cycling and so on.

- However, to ensure a better response in city air quality management, it is must to develop an integrated system. Regarding the air quality management, the Bangladesh government has some effective strategies and guidelines but there is no adequate monitoring and implementation programs. But these are very important not only to mitigate the air pollution but also to allow the owners of source points for getting the information they need to monitor and improve and upgrade their system further.

- Generally, the decision-makers of Bangladesh typically follow a traditional method to the air control system. In the manufacturing fields, this system primarily lays a set of standards for polluters. This could be a positive achievement for just only industrial sector, but the government can extend the process towards punishing all kinds of polluters and provide economic stimuli to mitigate emissions.

- While a limited incentive system is currently in operation, it may be extended to involve numerous initiatives and activities such as tax incentives related to pollution, waste-treatment subsidies, waste disposal rebate schemes, etc.

- It is true that the air control management policy mostly depends on the regulatory authorities of Bangladesh working within the missions-visions and network of the SDGs, declared by the UN and we should promote greater public involvement in the system.

- The Bangladesh government, different types of mass media along with environmental activists and organizations should encourage the mass people of Dhaka city along with the other people of the country to contribute something good from their positions to make the Dhaka city as the green city, as the living city as well as air-pollution free city. The proper direction, counselling and motivation from the government level and other concerned levels can motivate the people of Dhaka city to reduce less air pollution.

- Finally, the Bangladesh government should identify the real causes of air pollution in Dhaka city as per the given directions of the Supreme Court of Bangladesh. On 27 November 2019, the High Court Bench of Bangladesh Supreme Court directed the authorities concerned to identify the causes of air pollution.

\section{CONCLUSION}

Air is one of the precious natural resources and it is impossible for human beings to live without it. It is well known that fresh air is good to improve blood pressure and heart rate; it makes us happier; fresh air strengthens our immune system; it cleans our lungs; it gives us more energy and a sharper mind. But the pollution of air can interfere with human activities, and it is only in recent times that mankind has realized to what extent this interference is sustainable. All the air pollutants are hazardous to health; for instance, short-term exposure to $\mathrm{SO}^{2}$ to humans causes aggravation of asthma and chronic bronchitis. Moreover, different types of air pollutants affect human health in different ways. Those pollutants are also responsible for the lung infection, pulmonary infection and sometimes increase death rate. So, air pollution in Dhaka city has become the most important issue in the present context. The present study reveals that 70 per cent of the city's roadsides are severely polluted. Consequently, its impacts on the health of the city dwellers are very alarming. The presence of $\mathrm{PM}, \mathrm{SO}_{2}$ and $\mathrm{Pb}$ levels in the air of Bangladesh exceeds the acceptable limits set by WHO resulting pollution. The ambient level of $\mathrm{NO}_{2}$ is, as defined by the air quality standard, regularly lower than the acceptable limit. Though the available time-series data are insignificant, accessible air quality indicators suggest that air of Dhaka city is getting worse day by day. Some positive measures, such as replacement of 2-stroke 3-wheelers with 4-stroke and the introduction of unleaded gasoline, have improved air quality but are still insufficient to track and control motor vehicles' pollution. Limited capacity of roads in comparison with growing traffic volumes and lack of traffic management have also hampered the air quality.

\section{ACKNOWLEDGEMENTS}

The author is thankful to Mrs. Eva Armin (a former student of Bangabandhu Sheikh Mujibur Rahman Agricultural University, Bangladesh); Professor Dr. M. Habibur Rahman (BUET, Bangladesh) and A. Al-Muyeed (DUET, Bangladesh) for sharing their necessary information and facilities required for this work. 


\section{REFERENCES}

Alam, B., Rahman, H. and Jaigirdar, A. 1999. Ambient air quality at roadside in Dhaka City. J. of Poll. Res., 18(2): 65-72.

Biswas, K. 2020. Impact of unleaded gasoline introduction on the concentration of lead in the air of Dhaka, Bangladesh. J. of Air \& Waste Manag. Asso., 53(11): 1355-1362.

Begum, A., Hossain, A. and Saroar, G. 2011. Sources of carbonaceous materials in the airborne particulate matter of Dhaka. Asian, J. of Atmo. Env., 5(4): 237246.

Chafe, Z.A., Brauer, M. and Smith, K.R. 2014. Household cooking with solid fuels contributes to ambient $\mathrm{PM}_{2.5}$ air pollution and the burden of disease. Env. Health Pers., 122(12): 1314-1320.

EEA, European Environment Agency. 2016. Air quality in Europe-2016 report, Luxembourg Publications Office of the European Union. Retrieved from http://www.eea.europa.eu

Faiz, A., Weaver, C.S. and Walsh, M.P. 1996. Air Pollution from Motor Vehicles: Standards \& Technologies for Controlling Emissions. WB Publishers., pp.11-12.

Faruque, A. A. 2017. Environmental law: global and Bangladesh context. New Warsi Book Corporation., pp. 374.

Flossmann, F.I., Hall, W.D. and Pruppacher, H.R. 2008. A theoretical study of the wet removal of atmospheric pollutants: Part-I. The redistribution of aerosol particles captured through nucleation and impaction scavenging by growing cloud drops. J. of Atmos. Sci., 42(1): 583-606.

Franchini, M. and Mannucci, P.M. 2019. Impact on human health of climate changes. Euro. J. of Int. Med., 26(1): 1-5.

Gonzalez., Pertega, S. and Garnelo, L. 2013. Truck traffic related air pollution associated with asthma symptoms in young boys: A cross sectional study. J. of Pub. Health., 127(3): 275-281.

Kannan, S., Misra, D.P. and Dvonch, J.T. 2007. Exposures to airborne particulate matter and adverse perinatal outcomes: A biologically plausible mechanistic framework for exploring potential. Env. Health Perspec., 11)114): 1636-1642.

Lin, Y., Zhou L. and Xu, J. 2017. The impacts of air pollution on maternal stress during pregnancy. Sci Rep., 7: 40956 DOI: 10.1038/srep40956

Liu, F., Zhao, Y. and Liu. Y.Q. 2014. Asthma and asthma related symptoms in 23326 Chinese children in relation to indoor and outdoor environmental factors: The Seven Northeastern Cities (SNEC) study. Sci. Total Env., 497(498): 10-17.

Mahmud, I. 2011. Air pollution cost TK 124 billion a year in Dhaka city, Bangladesh Independent News. Retrieved from: http:// www.bdinn.com

Mc, C., Culligan, P. and Nieuwenhuijsen, M. J. 2007. Respiratory effects of exposure to diesel traffic in persons with asthma. N. Engl. J. Med., 357(23): 2348-2358.

Nishimura, K., Galender, J.M. and Roth, L.A. 2013. Early life air pollution and asthma risk in minority children. Ame. J. of Respir. Crit. Care Med.,_188(3): 309-318.

Padula, A. M., Ira B. and Tager, S. L. 2013. The Association of Ambient Air Pollution and Traffic Exposures with Selected Congenital Anomalies in the San Joaquin Valley of California. Am. J. Epidemiol., 177(10): 1074-1085.

Staff Reporter 2019. Identify causes of air pollution in capital. The Independent, 2019, November 27, 2019, Retrieved from http://www. theindependentbd.com/printversion/details/225366.

World Health Organization (WHO). World Report 2018: Annual review of human rights around the globe. Retrieved from: http://www.hrw.org

Yamamoto, S., Phalkey, R. and Malik, A. 2014. A systematic review of air pollution as a risk factor for cardiovascular disease in South Asia: Limited evidence from India and Pakistan. Int. J. Hyg. Environ. Health, 217(2-3): 133-144.

Zaidi, S.M., Moin, O. and Khan, J.A. 2011.Second-hand smoke in indoor hospitality venues in Pakistan. Int. J. of Tuberc Lung Dis., 15(7): 972-977. 